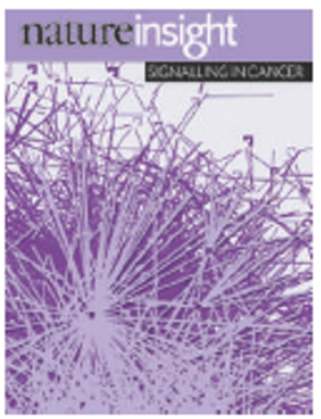

Cover illustration Adapted from a network graph of protein-protein interactions in J.-F. Rual et al Nature 437, 1173-1178 (2005).

Editor, Nature
PhilipCampbell
Insights Publisher
Sarah Greaves
Insights Editor
Lesley Anson
Production Editors
Nell Boase
Rebecca Craven
Senior Art Editor
Martin Harrison
Art Editor
Nik Spencer
Layouts
Jane Wright
Sponsorship
Claudia Banks
Claire Hines
Production
Jocelyn Hilton
Marketing
Robin Brown
EditorialAssistant
Laura Shaw

\section{SIGNALLING IN CANCER}

T he past 30 years have led from the discovery of the first cancer-causing gene, or 'oncogene,' to the emergence of a new generation of cancer therapies

- those targeted at specific signalling molecules. The signalling pathways controlling cell growth and differentiation are almost invariably altered in cancer. These interconnected pathways are being deciphered, but understanding the alterations that lead to cancer and correcting them is a substantial challenge. The reviews in this Insight discuss the molecular circuitry regulating several key cellular processes, and illustrate how defining the signalling mechanisms is aiding the development of therapies.

Among the key pathways are those controlling cell proliferation, which coordinate a response to the cellular environment, with the mTOR kinase as a critical node. Tumour development is influenced by infections and inflammation, and the complex role of the nuclear factor- $\mathrm{kB}$ transcription factors is being unravelled. Expansion of tumour cells depends on nutrient supply and vascularization, which is orchestrated by the transcription factor known as HIF. And the metastatic spread of primary tumours to other organs is facilitated by many signalling pathways; exploring their functional contributions has just begun.

Evaluating signalling molecules as drug targets is important for prioritizing research, even though we cannot predict the success of drugs in the clinic. Still, with several inhibitors of signalling molecules now approved for clinical use, and more in the pipeline, there is reason to celebrate 30 years of oncogene research. We hope these reviews provide a glimpse of recent excitements. Thanks are due to the authors for their contributions and to reviewers for their input.

We are pleased to acknowledge the financial support of Genentech and Pfizer in producing this Insight. As always, Nature carries sole responsibility for editorial content and peer review.

\section{Alex Eccleston, Senior Editor Ritu Dhand, Chief Biology Editor}

\section{REVIEWS}

424 Ras, PI(3)K andm TOR signalling controls tumour cell growth
R. J. Shaw \& L. C. Cantley

431 Nuclear factor-kB in cancer development and progression M. Karin

437 Hypoxia signalling in cancer and approaches to enforce tumour regression
J. Pouysségur, F. Dayan \& N.M. Mazure

444 New signals from the invasive front
G. Christofori

451 Validating cancer drug targets

J.D. Benson, Y.-N. P. Chen,

S. A. Cornell-Kennon, M. Dorsch,

S. Kim, M. Leszczyniecka,

W. R. Sellers \& C. Lengauer

457 Mechanisms of drug inhibition of signalling molecules

J. S. Sebolt-Leopold \&

J.M. English

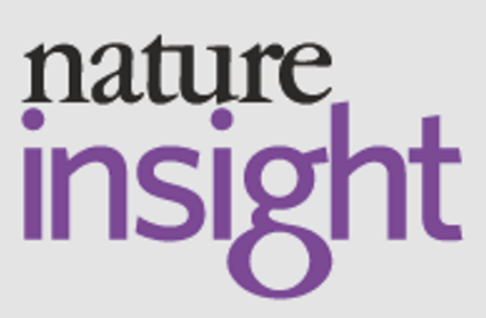

